\title{
PENGARUH PENDEKATAN PEMBELAJARAN BRAIN BASED LEARNING (BBL) TERHADAP KEMAMPUAN BERPIKIR KREATIF MATEMATIKS TERHADAP SISWA
}

\author{
IDA FARIDA \\ Pascasarjana PMIPA, Universitas Indraprasta PGRI, Jakarta

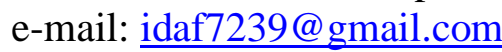

\begin{abstract}
ABSTRAK
Menghadapi era disrupsi yang terjadi saat ini, pembelajaran dilakukan untuk siswa harus mengarah pada pengembangan keterampilan berpikir tingkat tinggi. Kemampuan ini merupakan salah satu bekal bagi peserta untuk menghadapi persaingan di masa yang akan datang. Kemampuan berpikir kreatif matematis merupakan salah satu kemampuan berpikir tingkat tinggi dalam kemampuan matematika. Kemampuan berpikir kreatif matematis siswa masih rendah dan kurang perhatian dalam pelaksanaan pembelajaran matematika. Masalah ini membutuhkan upaya untuk mengatasi masalah. Salah satu upaya yang dapat dilakukan guru untuk mengembangkan kreativitas kemampuan berpikir adalah dengan menerapkan model pembelajaran Brain Based Learning. Studi ini bertujuan mendeskripsikan perkembangan kemampuan berpikir kreatif matematis siswa melalui Model Pembelajaran Berbasis Otak. Peserta adalah enam siswa yang dipilih dari 80 siswa kelas VII di SMP Negeri 1 Pamarayan. metode yang digunakan adalah metode eksperimen dengan dua kelas, yaitu kelas eksperimen yang diberi perlakukan pembelajaran konsep bangun datar dengan pendekatan pembelajaran Brain Based Learning dan kelas kontrol yang diberi perlakuan dengan metode konvensional. Sampel berjumlah 80 siswa, diambil dengan menggunakan teknik Cluster Random Sampling. Instrumen yang digunakan adalah kemampuan berpikir kreatif matematika siswa pada pokok bahasan bangun datar. Hasil perhitungan dengan menggunakan rumus uji-t, hasilnya diperoleh $\mathrm{t}$ hitung sebesat 7,291 Lebih besar dari pada $\mathrm{t}$ tabel 1,994 pada taraf signifikasi $\alpha=0,05$ dengan demikian, dapat dikemukakan bahwa penggunaan pendekatan pembelajaran Brain Based Learning berpengaruh signifikan kemampuan berpikir kreatif matematika siswa pada pokok bahasan bangun datar dikelaas VII SMP Negeri 1 Pamarayan
\end{abstract}

Kata Kunci: Pendekatan Pembelajaran Brain Based Learning (BBL), Kemampuan Berpikir Kreatif Matematiks

\footnotetext{
ABSTRACT

Facing the current era of disruption, learning done for students must lead to the development of higher order thinking skills. This ability is one of the provisions for participants to face competition in the future. Mathematical creative thinking ability is one of the higher order thinking skills in mathematical abilities. Students' mathematical creative thinking ability is still low and lacks attention in the implementation of mathematics learning. This issue requires effort to resolve the issue. One of the efforts that teachers can make to develop creative thinking skills is to apply the Brain Based Learning learning model. This study aims to describe the development of students' mathematical creative thinking skills through the Brain-Based Learning Model. The participants were six students who were selected from 80 grade VII students at SMP Negeri 1 Pamarayan. The method used is an experimental method with two classes, namely the experimental class which is treated with learning the concept of flat shapes with a Brain Based Learning approach and the control class which is treated with conventional methods. A sample of 80 students was taken using the Cluster Random Sampling technique. The instrument used is the students' mathematical creative thinking ability on the subject of flat shapes. The results of calculations using the t-test formula, the results obtained that the $t$ count is 7.291. It is greater than $t$ table 1.994 at the significance level $\alpha=0.05$. Thus, it can be stated that the use of the Brain Based Learning approach has a significant effect on students' creative thinking skills in mathematics. the subject of flat wake in class VII SMP Negeri 1 Pamarayan
} 
Keywords: Brain Based Learning (BBL) Approach, Mathematical Creative Thinking Ability

\section{PENDAHULUAN}

Matematika merupakan ilmu universal yang mendasari perkembangan teknologi moderen dan mempunyai peran penting memajukan daya pikir manusia (Ibrahim, $2008: 35$ ). Mata pelajaran matematika perlu diberikan kepada semua peserta didik dari sekolah dasar untuk membekali peserta didik dengan kemampuan befikir logis, análisis, sistematis, kreatif, serta kemampuan bekerjasama. Kompetensi tersebut diperlukan agar peserta didik dapat memiliki kemampuan memperoleh, mengelola dan memanfaatkan informasi untuk bertahan hidup pada keadaan yang selalu berubah, tidak pasti dan kompetetif.

Dalam bidang matematika terdapat istilah hard skills matematika. Jenis-jenis hard skills matematika menurut Hendriana dalam Darwanto (2019:23) adalah sebagai berikut: 1) kemampuan pemahaman matematis; 2) kemampuan penalaran matematis; 3) kemampuan pemecahan masalah matematis; 4) kemampuan komunikasi matematis; 5) kemampuan koneksi matematis; 6) kemampuan berpikir logis matematis; 7) kemampuan berpikir kritis matematis; dan 8) kemampuan berpikir kreatif matematis. Kedelapan jenis hard skills tersebut sesuai dengan amanat Undang-Undang dan juga tujuan pendidikan nasional merupakan bagian dari pendidikan dan kemampuan yang harus dimiliki oleh peserta didik agar tujuan pendidikan khususnya bidang matematika tercapai dan berkembang

Berpikir kreatif termasuk berpikir pada otak kanan, yaitu dengan fokus membuat dan mengomunikasikan hubungan baru yang lebih bermakna. Menurut Surya (2015:120) berpikir kreatif adalah proses berpikir untuk: memperbanyak kemungkinan, menunda pertimbangan, memberikan kemungkinan baru dan yang tidak biasa, menggunakan kemampuan imajinasi dan intuisi, mengembangkan dan memilih alternatif, serta mempunyai banyak cara dan menggunakan titik pandang atau jawaban yang berbeda terhadap sesuatu

Semua perilaku manusia dikendalikan oleh otak. Demikian juga dengan peserta didik. Sifat masing-masing peserta didik juga akan berbeda, karena masing-masing memiliki perbedaan struktur komposisi otak. Adapun kunci membangun karakter pada peserta didik adalah dengan membangun struktur otak secara optimal sejak usia dini. Bangunan karakter inilah yang akan menjadi pembentuk arah hidup dan kehidupan mereka di masa depan jika mereka sudah tumbuh menjadi pribadi yang lebih dewasa.

Pada Siswa Kelas VII di SMP Negeri 1 Pamarayan Serang pada tahun ajaran 2020/2021, yang perolehan nilainya berkisar antara 3,0 sampai 5,0 atau rata-ratanya 4,5 dan hanya ada siswa antara 3 anak sampai 5 anak dalam satu kelas itu mendapat nilai di atas 5 atau di atas 2 rata-rata kelas. Berdasarkan nilai tersebut penulis melihat ada beberapa faktor yang mempengaruhi yaitu: 1)Kurangnya ketajaman penalaran dan kurangnya algoritma pada diri siswa. 2)Kurangnya motivasi dan minat belajar siswa itu sendiri. 3) Dan atau kurangnya prasyarat pendukung di dalam diri siswa untuk setiap mengikuti pelajaran matematika.

Oleh karena itu, perlu bagi para pendidik untuk memiliki pribadi yang lembut agar menjadi tempat pertumbuhan karakter yang positif bagi anak. Selain karakter pendidik, lingkungan sekolah juga menjadi penentu perkembangan karakter peserta didik. Maka ada anjuran untuk memilih sekolah yang bebas dari ketakutan, beban, ancaman, dan ejekan. Kalau mungkin, memilih sekolah yang memiliki program eksplisit pendidikan karakter, seperti super brain (brain based learning) integrated learning, cooperative learning, contextual learning, dan lainnya.

\section{METODE PENELITIAN}

Metode penelitian yang digunakan dalam penelitian ini adalah metode eksperimen yang merupakan metode penelitian yang paling produktif, karena apabila penelitian tersebut dilakukan dengan baik maka dapat menjawab hipotesis yang utamanya berkaitan dengan hubungan sebab akibat. Disamping itu, penelitian ekperimen dilakukan oleh peneliti dengan 
tujuan mengatur situasi dimana pengaruh variabel terhadap satu atau beberapa variabel terkait dapat diidentifikasi.

Metode eksperimen digunakan untuk mengetahui dampak yang diakibatkan oleh pendekatan pembelajaran Brain Based Learning (BBL) terhadap kemampuan berpikir kreatif matematika siswa. Selain itu, metode eksperimen menggunakan suatu percobaan yang dirancang khusus guna membangkitkan data yang diinginkan untuk menjawab pertanyaan penelitian, yang dimaksud dengan "percobaan" ialah bagian penelitian yang membandingkan dua kelompok sasaran penelitian. Satu kelompok diberikan perlakuan khusus dan satu kelompok lagi dikendalikan pada suatu keadaan yang pengaruhnya dijadikan perbandingan, kelompok kedua dinamakan kelompok kendali, kelompok kontrol atau kelompok perbandingan. Setelah bahan ajaran selesai, kedua kelas diberikan postest. Dari postes akan dianalisis untuk melihat pengaruh dari dua model pembelajaran tersebut.

\section{HASIL DAN PEMBAHASAN}

\section{Kemampuan Berpikir Kreatif Matematiks}

Proses berpikir terbentuk dari pribadi seseorang, oleh karena itu kemampuan berpikir kreatif seseorang dipengaruhi juga oleh pribadi yang kreatif yang akan mendorong dari dalam untuk berkreasi. Menurut Rogers (dalam Munandar 2012:34) tiga kondisi dari pribadi kreatif adalah: 1) Keterbukaan terhadap pengalaman; 2) Kemampuan untuk menilai situasi sesuai dengan patokan pribadi seseorang (Internal locus of evaluation); 3) Kemampuan untuk bereksperimen, untuk bermain dengan konsep-konsep.

Populasi penelitian ini meliputi seluruh siswa kelas VII SMPN 1 Pamarayan Kabupaten Serang tahun pelajaran 2012/2013.

Tabel 1. Daftar Siswa Kelas VII SMPN 1 Pamarayan

\begin{tabular}{|c|c|c|c|c|l|}
\hline \multirow{2}{*}{ No } & \multirow{2}{*}{ Kelas } & \multicolumn{2}{|c|}{ Siswa } & \multirow{2}{*}{ Jumlah } & \multirow{2}{*}{ Keterangan } \\
\cline { 3 - 5 } & & Laki-laki & Perempuan & & \\
\hline 1 & VII A & 17 & 23 & 40 & Kontrol \\
\hline 2 & VII B & 18 & 22 & 40 & \\
\hline 3 & VII C & 17 & 23 & 40 & Eksperimen \\
\hline 4 & VII D & 20 & 20 & 40 & \\
\hline 5 & VII E & 19 & 21 & 40 & \\
\hline 6 & VII F & 19 & 22 & 40 & \\
\hline 7 & VII G & 20 & 21 & 41 & \\
\hline 8 & VII H & 18 & 23 & 41 & \\
\hline Jumlah & 8 Kelas & 148 & 175 & 323 & \\
\hline
\end{tabular}

Hasil perondoman terhadap semua kelas VII, diperoleh kelas VII A sebagai kelas kontrol dan kelas VII C sebagai kelas eksperimen. Masing-masing kelas berjumlah 40 siswa. Dengan demikian jumlah sampel keseluruhan adalah 80 siswa.

Tabel 2. Daftar Sampel

\begin{tabular}{|c|c|c|c|c|}
\hline \multirow{2}{*}{ No } & \multirow{2}{*}{ Kelas } & \multicolumn{2}{|c|}{ Siswa } & \multirow{2}{*}{ Jumlah } \\
\cline { 3 - 4 } & & Laki-laki & Perempuan & \\
\hline 1 & VII A & 17 & 23 & 40 \\
\hline 2 & VII C & 17 & 23 & 40 \\
\hline Jumlah & 2 Kelas & 34 & 46 & 80 \\
\hline
\end{tabular}

Hasil perhitungan validitas butir soal yang telah diuji cobakan pada soal tes kemampuan berpikir kreatif pada pokok bahasan bangun datar yang terdiri dari 4 soal dapat dilihat pada tabel 3.7 dibawah ini: 
TEACHING : Jurnal Inovasi Keguruan dan IImu Pendidikan

Vol. 1. No. 4 Desember 2021 e-ISSN : 2775-7188 | p-ISSN : 2775-717X

Tabel 4. Hasil Perhitungan Validitas Soal

\begin{tabular}{|c|c|c|}
\hline Nomor Soal & Koefisien Korelasi & Keterangan \\
\hline 1 & 0,76 & Valid \\
\hline 2 & 0,84 & Valid \\
\hline 3 & 0,24 & Tidak valid \\
\hline 4 & 0,74 & Valid \\
\hline
\end{tabular}

Tabel 5. Klasifikasi Daya Pembeda

\begin{tabular}{|l|l|}
\hline \multicolumn{1}{|c|}{ Kriteria } & \multicolumn{1}{c|}{ Keterangan } \\
\hline D: $0,00-0,20$ & Jelek \\
\hline D: $0,20-0,40$ & Cukup \\
\hline D: $0,40-0,70$ & Baik \\
\hline D: $0,70-1,00$ & Sangat Baik \\
\hline D: Negatif, & $\begin{array}{l}\text { Tidak baik } \\
\text { Soal dengan nilai D } \\
\text { negatif sebaiknya } \\
\text { dibuang }\end{array}$ \\
\hline
\end{tabular}

(Arikunto, 2011:281)

Tabel 6. Ringkasan Hasil Uji-t Postes Kemampuan Berpikir Kreatif Matematika

\begin{tabular}{|c|c|c|c|c|c|c|}
\hline Kelompok & $\mathrm{N}$ & $\overline{\mathrm{x}}$ & $\mathrm{S}^{2}$ & $\mathrm{t}_{\text {hitung }}$ & $\mathrm{t}_{\text {tabel }}$ & Kesimpulan \\
\hline Eksperimen & 40 & 63,03 & 127,87 & \multirow{2}{*}{7,291} & 1,994 & $\begin{array}{c}\text { Tolak } \mathrm{H}_{\mathrm{o}} \\
\text { Terima } \mathrm{H}_{\mathrm{i}}\end{array}$ \\
\hline Kontrol & 40 & 45,15 & 120,49 & & & \\
\hline
\end{tabular}

Berdasarkan hasil perhitungan dengan menggunakan statistik uji-t (perhitungan dapat dilihat pada lampiran) ternyata perbedaan nilai rata-rata hasil belajar antara kelas eksperimen dengan kelas kontrol merupakan perbedaan yang sebenarnya, sehingga dapat disimpulkan bahwa dikelas VII SMP Negri 1 Pamarayan, hasil belajar matematika siswa yang pembelajarannya menggunakan pendekatan pembelajaran Brain Based Learning (BBL) lebih baik daripada yang menggunakan model pembelajaran konvensional.

Data Pretes Kelas Eksperimen, Berdasarkan hasil perhitungan data hasil penelitian tes kemampuan berpikir kreatif pada pokok bahasan bangun datar diperoleh data nilai yaitu nilai tertinggi 41 dan nilai terendah 0 nilai rata-ratanya yaitu 15,78 median 14,20 dan modus sebesar 11,31. Bila diinterprestasikan maka sekor yang berada didalam inteval atas 7-13 merupakan skor yang palilng banyak diperoleh siswa kelas eksperimen, yaitu sebanyak 37,5\% rata-rata nilai yang diperoleh siswa dalam interval tersebut yaitu 10,43.

Data Pretes Kelas Kontrol, Berdasarkan hasil perhitungan data hasil penelitian tes kemampuan berpikir kreatif pada pokok bahasan bangun datar diperoleh data nilai yaitu nilai tertinggi 41 dan nilai terendah 0 nilai rata-ratanya yaitu 17 median 15,60 dan modus sebesar 11,63. Bila diinterprestasikan maka sekor yang berada didalam inteval atas 7-13 merupakan skor yang palilng banyak diperoleh siswa kelas kontrol, yaitu sebanyan 35\% rata-rata nilai yang diperoleh siswa dalam interval tersebut yaitu 11,52.

Data Postes Kelas Eksperimen, Berdasarkan hasil perhitungan data hasil penelitian tes kemampuan berpikir kreatif pada pokok bahasan bangun datar diperoleh data nilai yaitu nilai tertinggi 83 dan nilai terendah 42 nilai rata-ratanya yaitu 63,03 median 78,06 dan modus sebesar 59,70. Bila diinterprestasikan maka sekor yang berada didalam inteval atas 56-62 merupakan skor yang palilng banyak diperoleh siswa kelas eksperimen, yaitu sebanyak 22,5\% rata-rata nilai yang diperoleh siswa dalam interval tersebut yaitu 60,98. Dengan demikian proses pembelajaran yang menggunakan pendekatan pembelajaran Brain Based Learning (BBL) mendapatkan respon baik dari siswa. 
Data Postes Kelas Kontrol, Berdasarkan hasil perhitungan data hasil penelitian tes kemampuan berpikir kreatif pada pokok bahasan bangun datar diperoleh data nilai yaitu nilai tertinggi 66 dan nilai terendah 25 nilai rata-ratanya yaitu 45,15 median 44,72 dan modus sebesar 43,17. Bila diinterprestasikan maka sekor yang berada didalam inteval atas 39-45 merupakan skor yang palilng banyak diperoleh siswa kelas kontrol, yaitu sebanyan $22,5 \%$ rata-rata nilai yang diperoleh siswa dalam interval tersebut yaitu 42,43. Dengan demikian proses perhitungan yang tidak menggunaka pendekatan pembelajaran Brain Based Learning (BBL) mendapatkan respon kurang baik dari siswa.

Pendekatan pembelajaran yang digunakan harus mencakup kerangka yang menyeluruh tentang proses belajar mengajar yang didalamnya tersurat secara sistematis bahan pelajaran yang diberikan, urutan pemberian bahan, keterlibatan siswa, teknik penyajian serta teknik pengulang dalam rangka menumbuhkan berbagai keterampilan, dalam bentuk program satuan pengajaran yang dibuat oleh guru sebelum mengajar.

Jadi, dapat disimpulkan bahwa pendekatan pembelajaran dapat diartikan sebagai titik tolak atau sudut pandang kita terhadap proses pembelajaran, yang merujuk pada pandangan tentang terjadinya suatu proses yang sifatnya masih sangat umum.

Oleh karena itu, salah satu pendekatan pembelajaran untuk memenuhi tuntutan tersebut ialah pendekatan pembelajaran Brain Based Learning.

\section{Brain Based Learning}

Brain Based Learning (BBL) (Jensen, 2008:12) adalah pembelajaran yang diselaraskan dengan cara otak yang didesain secara alamiah untuk belajar. Pembelajaran Brain-Based Learning merupakan pembelajaran yang mampu memberikan ruang pada siswa untuk berpikir dengan lapang tanpa tekanan, lingkungan belajar yang mendukung, dan penuh stimulus yang memacu kreativitas berpikir.

Dalam menerapkan pendekatan pembelajaran brain based learning, ada beberapa hal yang harus diperhatikan karena akan sangat berpengaruh pada proses pembelajaran, yaitu lingkungan, gerakan dan olahraga, musik, permainan, peta pikiran (mind map), dan penampilan guru.

Tahap-tahap pembelajaran dengan menggunakan Pendekatan Pembelajaran Brain Based Learning (BBL) yang diungkapkan Jensen (2008:484-490 ) yaitu:

1. Pra-Pemaparan: Pra-pemaparan membantu otak membangun peta konseptual yang lebih baik.

2. Persiapan: Dalam tahap ini, guru menciptakan keingintahuan dan kesenangan.

3. Inisiasi dan akuisi: Tahap ini merupakan tahap penciptaan koneksi atau pada saat neuronneuron itu saling berkomunikasi satu sama lain.

4. Elaborasi: Tahap elaborasi memberikan kesempatan kepada otak untuk menyortir, menyelidiki, menganalisis, menguji, dan memperdalam pembelajaran.

5. Inkubasi dan memasukkan memori: Tahap ini menekankan bahwa waktu istirahat dan waktu untuk mengulang kembali merupakan suatu hal yang penting.

6. Verifikasi dan pengecekan keyakinan: Dalam tahap ini, guru mengecek apakah siswa sudah paham dengan materi yang telah dipelajari atau belum. Siswa juga perlu tahu apakah dirinya sudah memahami materi atau belum.

7. Perayaan dan integrasi: Tahap ini menanamkan semua arti penting dari kecintaan terhadap belajar.

Riset (Given, 2007:67) menunjukkan bahwa otak mengembangkan lima sistem pembelajaran primer yaitu emosional, sosial, kognitif, fisik dan reflektif. Jika guru memahami bagaimana sistem pembelajaran primer (emosional, sosial, kognitif, fisik, reflektif) berfungsi, maka mengajar akan lebih efektif dan merasakan kegembiraan lebih besar dalam mengajar.

Agar emosi dapat berperan secara optimal, maka otak emosi membutuhkan suasana yang cocok dengan konsep pendidikan yaitu proses belajar harus menyenangkan, memberikan pengalaman yang bermakana dan relevan, melibatkan aspek multi sensori manusia, memberikan pengalaman unik dan menantang. Sebuah penelitian mengungkapkan bahwa 
kognisi dan emosi saling mempengaruhi walaupun kognisi dan emosi berasal dari otak berbeda (Jensen, 2007:9). Emosi positif dapat meningkatkan pengetahuan dan keterampilan, sedangkan emosi negatif akan menghabat prestasi akademis. Tetapi emosi negatif berkembang untuk mengaktifkan sistem perhatian/pemecahan masalah otak sehingga system tersebut biasa merespon tantangan berbahaya (Given, 2007:79).

Sistem pembelajaran emosional otak menentukan individualitas seseorang. Guru harus menciptakan suasana kelas yang kondusif bagi keamanan emosional dan hubungan pribadi agar siswa belajar secara efektif. Guru yang memupuk emosional berfungsi sebagai mentor dan membantu siswa menemukan hasrat untuk belajar, dengan membimbing mereka mewujudakan target pribadi yang masuk akal, dan mendukung siswa dalam upaya untuk mencapai yang ditargetkan.

Pada umumnya siswa menganggap matematika menakutkan dan sulit sehingga membuat stres dan jenuh, maka diperlukan pembelajaran matemetika yang menyenangkan. Hal ini sejalan dengan sistem pembelajran emosional pada pendekatan brain based learning (BBL). Menurut Given (2007:80) dengan pembelajaran yang menyenangkan akan membuat koneksi atau hubungan antara belahan otak kanan dan kiri menjadi lebih cepat, sehingga lebih membuat siswa dapat berfikir tentang pemecahan masalah matematika.

\section{KESIMPULAN}

Berdasarkan hasil penelitian dan pembahasan yang telah diuraikan dapat disimpulkan bahwa pelaksanaan pembelajaran matematika dengan menggunaka pendekatan pembelajaran Brain Based Learning (BBL) dapat meningkatkan kemampuan berpikir kreatif siswa dalam belajar matematika.

Matematika adalah mata pelajaran pokok yang diajarkan disetiap jenjang pendidikan dasar bahkan hingga perguruan tinggi. Siswa beranggapan bahwa matematika sangat sulit dipahami. Siswa cenderung kurang tertarik untuk mempelajarinya. Guru sebagai pendidik siswa di kelas harus merubah persepsi siswa tentang belajar matematika.

Guru juga harus memotivasi siswa untuk lebih berminat mempelajari matematika sehingga dapat meningkatkan kemampuan bermatematika. Dengan kemampuan berpikir kreatif yang tinggi diharapkan kemampuan matematika siswa semakin baik.

Berdasarkan hasil penelitian, penggunaan pendekatan pembelajaran BBL dapat mempengaruhi kemampuan berpikir kreatif matematika siswa. Hal ini dapat ditarik kesimpulan bahwa dalam menguasai matematika yang perlu dimiliki oleh siswa adalah kemampuan berpikir kreatif. Siswa memiliki minat belajar yang baik diikuti pula dengan kemampuan matematika yang baik.

\section{DAFTAR PUSTAKA}

Andiyana, M. A., Maya, R., \& Hidayat, W. (2018). Analisis Kemampuan Berpikir Kreatif Matematis Siswa SMP Pada Materi Bangun Ruang. JPMI (Jurnal Pembelajaran Matematika Inovatif), (Daring), Vol.1(3): 239-248. Tersedia: https://journal.ikipsiliwangi.ac.id (27 Agustus 2019).

Arikunto, Suharsimi, (2011). Dasar-Dasar Evaluasi Pendidikan. Jakarta: Bumi Aksara

Darwanto, D. (2019). Hard Skills Matematik Siswa. Dalam Eksponen,(Jurnal Hard Skills Matematik Siswa (Pengertian dan Indikator)) (Daring), Vol.9 (1): 21-27. Tersedia: https://ojs.stkipmktb.ac.id (24 Agustus 2019).

Given. (2007). Brain Based Teaching. Bandung: Kalfa

Ibrahim dan suparni, (2008). Strategi Pembelajaran Matematika. Yogyakarta: Bidang Akadenik UIN Sunan Kalijaga

Iskandar. (2009). Psikologi Pendidikan (Sebuah Orientasi Baru). Cipayung: Gaung Persada (GP) Press.

Jensen, E. (2008). Pembelajaran Berbasis Kemampuan Otak: Cara Baru dalam Pengajaran dan Pelatihan. Yogyakarta: Pustaka Pelajar. 
Johnson, Elaine B. (2014). CTL Contextual Teaching \& Learning. Bandung: Kaifa Learning. Komalasari, Kokom (2010). Pembelajaran Kontekstual. Bandung: Refika Aditama

Munandar, Utami. (2012). Pengembangan Kreativitas Anak Berbakat. Jakarta: PT.Rineka Cipta.

Noer, S. H. (2009). Kemampuan Berpikir Kreatif Matematis Apa, Mengapa, dan Bagaimana? (pp. 521-526). In Lampung: Prosiding Seminar Nasional Penelitian, Pendidikan dan Penerapan MIPA Fakultas MIPA, Universitas Negeri Yogyakarta (Vol. 16).

Riyanto, Yatim. (2010). Paradigma Baru Pembelajaran. Jakarta: Kencana Prenada Media Grup.

Sanjaya, Wina. (2008). Strategi Pembelajaran: Berorientasi Standar Proses Pendidikan . Jakarta: Kencana Prenada Media Group.

Surya, Muhamad. (2015). Strategi Kognitif dalam Proses Pembelajaran. Bandung: Alfabeta 